\title{
Advancements and lingering challenges in addressing public health disasters
}

\author{
Phillip M. Singer \\ Department of Political Science, University of Utah, Salt Lake City, UT, USA \\ Correspondence to: Phillip M. Singer. Department of Political Science, University of Utah, 260 S. Central Campus Dr. Room 3345, Salt Lake City, UT \\ 84112, USA. Email: phillip.singer@poli-sci.utah.edu. \\ Comment on: Yang Z, Zeng Z, Wang K, et al. Modified SEIR and AI prediction of the epidemics trend of COVID-19 in China under public health \\ interventions. J Thorac Dis 2020;12:165-74.
}

Submitted Mar 25, 2020. Accepted for publication Apr 09, 2020.

doi: $10.21037 /$ jtd.2020.04.52

View this article at: http://dx.doi.org/10.21037/jtd.2020.04.52

The world was ill-equipped for the emergence and outbreak of coronavirus disease (COVID-19). As of the March 2020, 3 months after the appearance of the disease, there have been more than a quarter million confirmed cases around the world and more than 10,000 deaths (1). However, COVID-19 provides researchers, policymakers, and the public the opportunity to make methodological advancements on how to improve our response to this pandemic and to future public health disasters.

When looking over the sweep of history and prior disease outbreaks, the lack of preparation from policymakers, practitioners, and the public has been the rule, not the exception. Part of this lack of preparation has been a series of core challenges that combine to limit the response to public health disasters. The work of Yang et al. provides an important advancement for policymakers and researchers to overcome several of these core challenges. Yet, there still remains lingering challenges which we collectively face to limit future pandemics. Making advancements in our response to public health emergencies is particularly important as the likelihood and frequency of pandemics will increase as the world grows increasingly more interconnected through commerce, travel, and from the consequences of climate change $(2,3)$.

One of the core challenges related to responding to pandemics and novel disease outbreaks, even with our collective prior experiences, is knowing which of the different policy tools are effective at containing the disease. Governments have an arsenal of different policy interventions they can make to reduce the spread of an epidemic. Though importantly, not all interventions are created equally. All interventions have costs, both economic and social, associated with them. Policymakers are faced with the balancing being overly aggressive when the disease does not call for such an approach, with doing too little and having a disease harm or kill more people (4). For example, the adoption of stringent quarantine practices may have the benefit of flattening the curve of a disease, but policymakers need information to know whether such an intervention creates more harm than what it would prevent, how high the curve may reach without adopting a strict quarantine, or what the effect adopting other interventions may have.

To this end, Yang et al. provide an important contribution to the growing literature of epidemics and policy response. The authors use Susceptible-Exposed-Infectious-Removed (SEIR) and artificial intelligence to help predict the extent of the COVID-19 epidemic. China, in response to the emergence of COVID-19, adopted a series of increasingly stringent preventive measures, including restrictions on travel, quarantines, and individual monitoring. Using a series of innovative methods, this research was able to closely predict the peak and size of the epidemic, predictions of future epidemics, and the effect of the control measures adopted by China (5). Chinese authorities were successfully at reducing the spread of COVID-19 through the policy interventions they adopted since the outbreak of the disease.

This latter point, of being able to understand the effect of each of the different approaches undertaken by the Chinese government in response to COVID-19, is particularly 


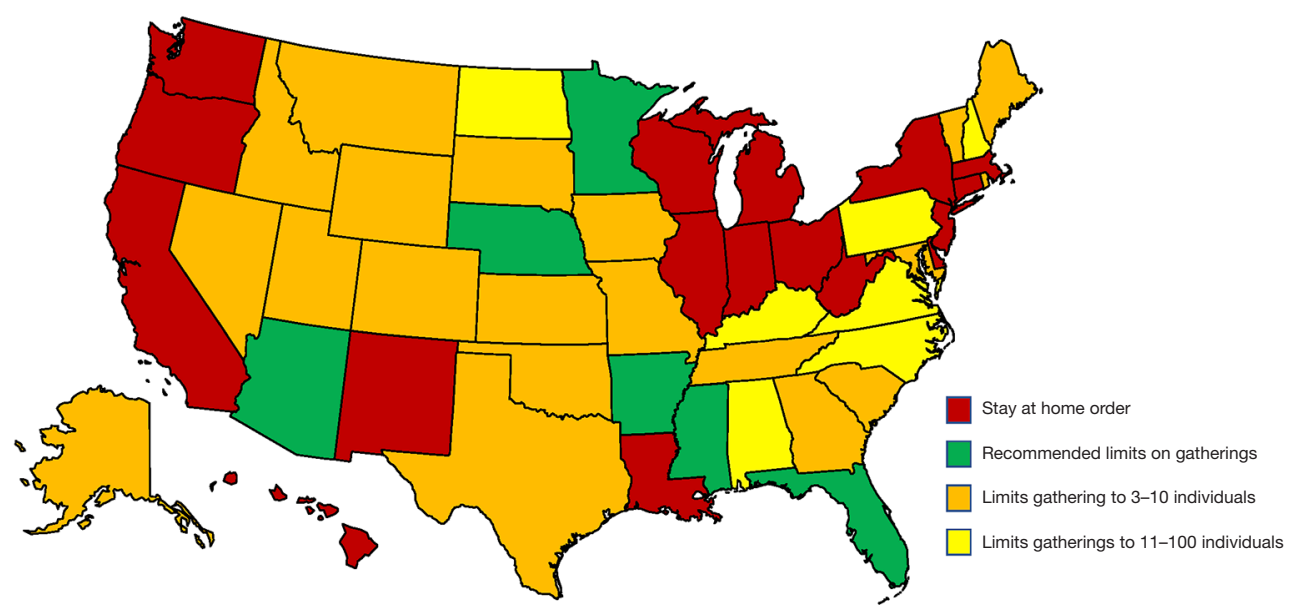

Figure 1 Variation in state limits on gatherings in the United States as of March 25, 2020.

important for containing future outbreaks. Policymakers and the public need not grasp wildly in the dark for whatever intervention is most politically or economically expedient. Rather, with further refinement, the work of Yang et al., along with other research that has emerged in the wake of COVID-19 (6-8), can improve policymakers and governments ability to address and respond to disease outbreaks and pandemics.

However, these improvements in modeling the effects of a disease outbreak stand in stark relief to the lingering challenges that policymakers face in responding to COVID-19 and future disease outbreaks. It is no longer enough that a single country selects the appropriate interventions to address a public health disaster. Rather, our collective response to a public health emergency is now only as strong as the country with the weakest response. Failure by any country to adequately respond to a disease outbreak can extend the spread of a disease, resulting in enclaves where the disease flourishes, constantly threatening an outbreak. It is not enough that China was able to adopt the interventions that they did, but they need to be concerned with the interventions taken by the 14 countries bordering them. The work from Yang et al. and others needs to be applied globally to rein in any future disease outbreaks.

Yet, this collective response to a public health emergency is shaped by differences individual countries political institutions and government capabilities, which can blunt the overall effectiveness of any one countries response to an epidemic. The United States is a case of these lingering challenges. Fragmentation of political institutions is common problem for health and public health systems globally, making a unified response to a public health emergency challenging (9). In the United States, public health governance and administration is shared across several different levels of government, with more than 90,000 local governments, 50 states, territories, counties, and the federal government that have responsibility for some aspect of public health.

In the United States this fragmentation has resulted in a patchwork of laws and regulations that govern how a state may respond to a public health emergency $(10,11)$. For example, by March 25, 2020, 17 states have adopted mandatory stay at home orders, while an additional 27 states have set varying limits on the size of gatherings that are allowed in their states (12). Six states, representing $18 \%$ of the total population of the United States has merely recommended that individuals not gather, though without any enforcement these recommendations are toothless (See Figure 1). With no restrictions on domestic travel, the United States' response to COVID-19 is limited by the variations in how individual states choose, or not, to adopt available interventions to slow the spread of the pandemic.

Fragmentation at the national level in the United States also blunts how any single country responds to COVID-19 (13). While the Trump administration has sought to frame their actions to COVID-19 as a "whole of government response", public health emergencies like COVID-19 sits at the juncture between public health, national security, and commerce, requiring many different institutions to work together in short order. In the case of COVID-19, the National Institutes of Health is responsible for conducting basic research and science around the novel 


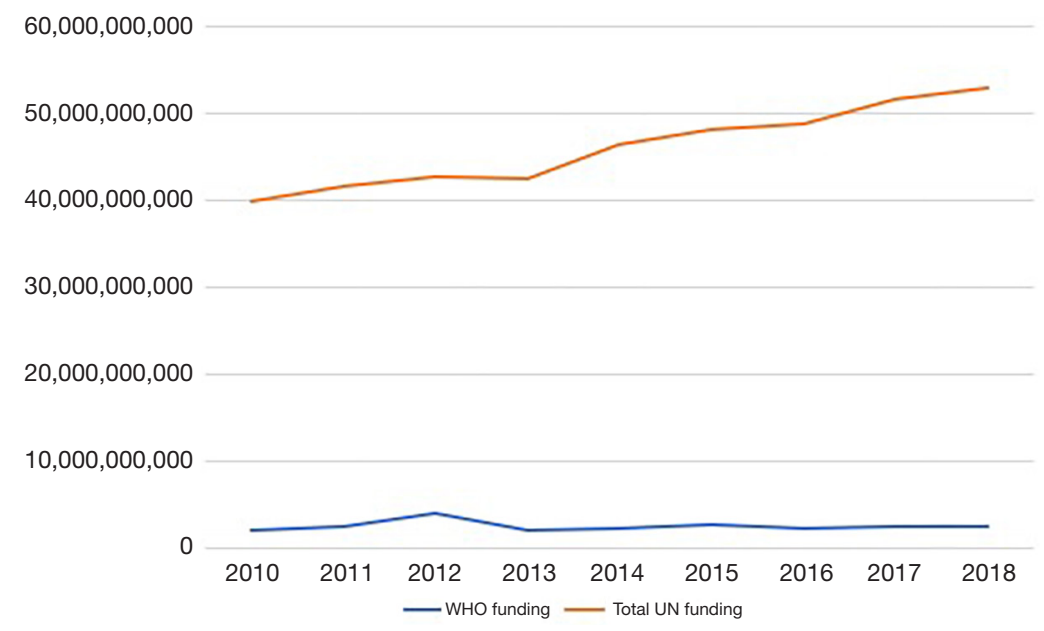

Figure 2 United Nations (UN) and World Health Organization (WHO) expenditures over time.

disease, the Centers for Disease Control and Prevention is responsible for tracking the disease, the Food and Drug Administration is responsible for ensuring vaccination and testing safety and efficacy, and the Department of Homeland Security is responsible for control measures related to travel. At the same time the agencies responsible for tax and commerce policy have to deal with the economic fallout of the virus. The United States is not unique in the level of fragmentation in its political and public health institutions, but highlights the lingering challenges for individual countries to adequately respond to a public health disaster.

The global effort to contain COVID-19, and importantly, to contain the next public health disaster, is hampered by the limits of global public health organizations. Across countries, there is wide variation in spending on health and public health, limiting our collective efforts to monitor, diagnose, and treat a public health disaster. Low-income countries spend an average of $\$ 10$ per person on health, compared to the average of $\$ 2,021$ in public funding for high-income countries (14). Yet, at the same time high-income countries are devoting less funding to development assistance in low-income countries to focus on health care (14) and the total percentage of United Nations (UN) expenditures for the primary global health organization, the World Health Organization (WHO), has decreased over the past decade (15) (See Figure 2).

But, how that money is spent is just as important as how much money is spent. Global shortages in personal protective equipment, mechanical ventilators, and the workforce necessary to provide care threatens public health capabilities and health system containment of COVID-19 around the world (16). The United States should be one of the most prepared countries to respond to a pandemic; no country spends more on health care, it has a welldeveloped health care system and has high levels of medical innovation (17). However, the United States does not spend the money in a way that is needed to adequately respond to the COVID-19 outbreak. For example, only $10 \%$ of all staffed beds in the United States are designated as Intensive Care Unit beds, the very type that are needed to care for individuals that are infected by COVID-19 (18) and less than half of all hospitals even have a single Intensive Care Unit bed (19). Rather, to combat pandemics policymakers should focus on the social determinants of health can reduce the spread of a disease by improving access to housing, food, and water. But countries vary substantially in the amount of social support they provide for their citizens (20).

The global efforts to contain the COVID-19 outbreak highlights the struggles that countries have and will continue to have to respond to public health disasters. Public health is focused on preventing the next outbreak, but it is largely ignored when an emergency is not occurring. We are newly reminded of the damage of failing to responding to a public health disaster when watching the damage incurred by failing to be prepared for the COVID-19 pandemic. Yet, the benefits of preparing for the next public health disaster are largely abstract and deferred, while the costs associated with that prevention are tangible and immediate. Preparing for and responding to the next public health disaster will require policymakers balance contentious issues like the restriction of individuals liberties and powerful economic interests with reducing the spread 
of disease. This means that public health is largely invisible, under-funded, and overlooked. Making it that much more difficult to adequately respond when the next public health disaster emerges.

Whether it is in the coming months or years, the current outbreak of COVID-19 will eventually subside. Breakthroughs like the ones from Yang et al. will contribute to improving the functioning of governments to respond to COVID-19 as well as future outbreaks. It is essential to look to the past to inform the future of how we response to the next public health disaster. Yet, there are many lingering challenges we face in responding to what comes next.

\section{Acknowledgments}

I wish to thank Charley Willison for helpful comments during the drafting of the editorial.

Funding: None.

\section{Footnote}

Provenance and Peer Review: This article was commissioned by the Editorial Office, Journal of Thoracic Disease. The article did not undergo external peer review.

Conflicts of Interest: The author has completed the ICMJE uniform disclosure form (available at http://dx.doi. org/10.21037/jtd.2020.04.52). The author has no conflicts of interest to declare.

Ethical Statement: The author is accountable for all aspects of the work in ensuring that questions related to the accuracy or integrity of any part of the work are appropriately investigated and resolved.

Open Access Statement: This is an Open Access article distributed in accordance with the Creative Commons Attribution-NonCommercial-NoDerivs 4.0 International License (CC BY-NC-ND 4.0), which permits the noncommercial replication and distribution of the article with the strict proviso that no changes or edits are made and the original work is properly cited (including links to both the formal publication through the relevant DOI and the license). See: https://creativecommons.org/licenses/by-nc-nd/4.0/.

\section{References}

1. Johns Hopkins University \& Medicine. Coronavirus
Resource Center. 2020. Available online: https:// coronavirus.jhu.edu/map.html

2. Markel H. When germs travel: six epidemics that invaded America since 1900 and the fears they unleashed. New York City: Random House, 2004.

3. Wu X, Lu Y, Zhou S, et al. Impact of climate change on human infectious diseases: Empirical evidence and human adaptation. Environ Int 2016;86:14-23.

4. Garrett L. Ebola's lessons: how the WHO mishandled the crisis. Foreign Affairs 2015;94:80.

5. Yang Z, Zeng Z, Wang K, et al. Modified SEIR and $\mathrm{AI}$ prediction of the epidemics trend of COVID-19 in China under public health interventions. J Thorac Dis 2020;12:165-74.

6. Li Q, Guan X, Wu P, et al. Early transmission dynamics in Wuhan, China, of novel coronavirus-infected pneumonia. N Engl J Med 2020;382:1199-207.

7. Wu JT, Leung K, Leung GM. Nowcasting and forecasting the potential domestic and international spread of the 2019-nCoV outbreak originating in Wuhan, China: a modelling study. Lancet 2020;395:689-97.

8. Read JM, Bridgen JR, Cummings DA, et al. Novel coronavirus 2019-nCoV: early estimation of epidemiological parameters and epidemic predictions. medRxiv. 2020.

9. Greer SL, Singer PM. The United States confronts Ebola: suasion, executive action and fragmentation. Health Econ Policy Law 2017;12:81-104.

10. Katz R, Vaught A, Formentos A, et al. Raising the yellow flag: state variation in quarantine laws. J Public Health Manag Pract 2018;24:380-4.

11. Katz R, Attal-Juncqua A, Fischer JE. Funding public health emergency preparedness in the United States. Am J Public Health 2017;107:S148-52.

12. National Governors Association. Coronavirus: what you need to know. 2020. Available online: https://www.nga. org/coronavirus/\#actions

13. Grossman G, Pierskalla JH, Dean EB, et al. Government fragmentation and public goods provision. Journal of Politics 2017;79:823-40.

14. World Health Organization. Global spending on health: a world in transition. Geneva: World Health Organization, 2019.

15. United Nations System. Expenditure by Agency. 2020. Available online: https://www.unsystem.org/content/FSF00-03

16. World Health Organization. Rational use of personal protective equipment for coronavirus disease (COVID-19): 
interim guidance, 27 February 2020. Geneva: World Health Organization, 2020.

17. Papanicolas I, Woskie LR, Jha AK. Health care spending in the united states and other high-income countries. JAMA 2018;319:1024-39.

18. American Hospital Association. Fast Facts on U.S. Hospitals, 2020. 2020. Available online: https://www.aha. org/statistics/fast-facts-us-hospitals

Cite this article as: Singer PM. Advancements and lingering challenges in addressing public health disasters. J Thorac Dis 2020;12(10):5254-5258. doi: 10.21037/jtd.2020.04.52
19. Tsai TC, Jacobson BH, Jha AK. American hospital capacity and projected need for COVID-19 patient care. 2020. Available online: https://www.healthaffairs.org/ do/10.1377/hblog20200317.457910/full/

20. Organisation for Economic Co-operation and Development. Social expenditure - aggregated data. 2020. Available online: https://stats.oecd.org/Index. aspx? DataSetCode=SOCX_AGG 